\title{
Evaluation of Canine Transpositions and Related Dental Anomalies in a Turkish Pediatric Population
}

\author{
Esra Oz'1(1), Zuhal Kırzıoglu1(i)
}

${ }^{1}$ Department of Pedodontics, Suleyman Demirel University Faculty of Dentistry, Isparta, Turkey.

Author to whom correspondence should be addressed: Esra Oz, Department of Pedodontics, Suleyman Demirel University Faculty of Dentistry, Isparta, Turkey. Phone: +90 2462113349 . E-mail: esrakaraagac@sdu.edu.tr.

Academic Editors: Alessandro Leite Cavalcanti and Wilton Wilney Nascimento Padilha

Received: 10 September 2019 / Accepted: 30 March 2020 / Published: 20 April 2020

How to cite this article: $\mathrm{Oz}$ E, Kırzıoglu Z. Evaluation of canine transpositions and related dental anomalies in a Turkish pediatric population. Pesqui Bras Odontopediatria Clín Integr. 2020; 20:e5100. https://doi.org/10.1590/pboci.2020.072

\begin{abstract}
Objective: To investigate the prevalence and characteristics of canine transpositions and to evaluate associated dental anomalies in a pediatric population. Material and Methods: This study was carried out by evaluating the panoramic radiographs of 11.750 patients ranging in ages from 6 to 17 presented to a pedodontic clinic over 5 years. The patients with canine transposition were included in the study. Age at diagnosis, gender, classification and location of transposition, presence of other dental anomalies were recorded. Differences were analyzed using the Chi-squared test. Results: Canine transposition was detected in 73 teeth from 69 patients $(0.6 \%)$. Transpositions were more common in girls than in boys $(55.1 \%)$. Transposed canine teeth were more frequently observed unilaterally (89\%). The most commonly found transposition type was type $2(42 \%)$. A total of $49.3 \%$ of 69 patients had retained primary canine teeth, $20.3 \%$ had congenitally missing teeth, and $11.6 \%$ had peg-shaped, microdont lateral incisors. Impacted teeth excluding third molars and taurodontism were also observed. Conclusion: Although the canine transpositions are generally asymptomatic in children in the period of growth and development, the importance of early diagnosis is crucial to prevent various clinical problems.
\end{abstract}

Keywords: Stomatognathic System Abnormalities; Tooth Abnormalities; Radiography, Panoramic; Child. 


\section{Introduction}

Dental anomalies occur as a result of interactions between genetic and environmental factors in the development of teeth. One of these anomalies, transposition, is a rare form of ectopic eruption and is defined as the displacement of two adjacent teeth [1].

Transposition can adversely affect dentition aesthetically and functionally [2]. It is essential to know the etiologic factors affecting its prevalence to take preventive measures. Although the etiology of transposition is unknown, genetic and environmental factors such as heredity, position changes in permanent tooth germs during odontogenesis, trauma, cystic lesions, odontoma, early tooth loss, delays in root resorption, and mechanical interference during permanent tooth eruption can result in transposition [3-8].

It has been reported that transposition is mostly seen in canine teeth and the incidence varies between 0.09-1.4\%. Differences in prevalence vary depending on ethnicity and whether patients are selected from patients in the general population or orthodontic clinics [3,9-15]. In studies of patients who presented to orthodontic clinics, more than 50 cases of transposition were reported, but these studies were also limited $[4,13,16,17]$.

Several studies have shown that canine transposition is often seen unilaterally in the upper jaw, but not simultaneously in both arches $[3,5,10,13]$. No report has been published on primary dentition [18]. According to the canine transposition classification, it is stated that upper canine-first premolar transposition is the most common and may be of genetic origin [5,13,19]. Although upper canine-lateral transposition was reported as the second most common [5], there are also studies indicating that it is the most common [3,14].

Canine transposition is associated with some characteristic features and dental anomalies, such as small peg-shaped upper lateral teeth, retained primary canine teeth, supernumerary teeth, impacted teeth, and congenitally missing teeth [13]. It was reported that case reports/series or the studies evaluating small sample groups caused this relationship to be low. In addition, they indicated the necessity of studies involving large sample groups [20].

The aim of this study was to determine the prevalence of canine transposition in panoramic radiographs of patients who were admitted to a pedodontic clinic between the ages of $6-17$ years between 2013-2017. Additionally, it was also determined the transposition types/localizations and other related dental anomalies in selected patients.

\section{Material and Methods}

\section{Study Design}

This cross-sectional study was carried out by evaluating the panoramic radiographs of patients who presented to the Department of Pedodontics at Suleyman Demirel University, Turkey, for over 5 years. Standard and good quality radiographs with full records were evaluated, and patients with canine transposition were included in the study.

\section{Data Collection}

All radiographs were taken with one device (Planmeca Promax, Helsinki, Finland) processed. Images were evaluated independently by two operators on the computer monitor. To estimate the reproducibility of diagnosis, all selected radiographs and records were examined again after one week later by the two operators. The inconsistencies between the findings were compared. The agreement between the operators was substantial (Kappa >90). 
Cases were classified according to the canine transposition classification [5]: Type 1: Maxillary canine-first premolar transposition (Mx.C.P1); Type 2: Maxillary canine-lateral incisor transposition (Mx.C.12); Type 3: Maxillary canine-first molar site transposition (Mx.C to M1); Type 4: Maxillary lateral incisor-central incisor transposition (Mx.12.11); Type 5: Maxillary canine-central incisor site transposition (Mx.C to 11); and Type 6: Mandibular lateral incisor-canine transposition (Mn.12.C)

The following were recorded for each subject: age at diagnosis, gender, classification and location of transposition, presence of other dental anomalies (hypodontia, taurodontism, retained primary canine, pegshaped lateral teeth, supernumerary teeth, impactions of teeth other than the transposed ones).

\section{Data Analysis}

Version 23.0 of the SPSS package program (IBM SPSS Inc., Chicago, Ill., USA) was used for recording and analyzing data. The Pearson chi-squared test was used to determine differences in the distribution of tooth transposition by gender. It was also used to assess side distribution and other dental anomalies. A p value $<0.05$ was considered statistically significant.

\section{Ethical Aspects}

Ethics committee approval for the study was obtained from Suleyman Demirel University Faculty of Medicine Clinical Research Ethics Committee (2019/113).

\section{Results}

Panoramic radiographs of 12.150 patients between 6-17 years of age who were admitted to a pedodontics clinic between 2013 and 2017 for any reason were examined. The good quality and standard radiographs of 11.750 patients with complete forms were evaluated. Among the evaluated panoramic radiographs, canine transposition was detected in 73 teeth from 69 patients (0.6\%), of which 38 were girls and 31 were boys. The mean age of these patients was $12.0 \pm 0.28$ (girls $=11.65 \pm 0.38$ and boys $=12.42 \pm 0.40)$.

The radiographic material was divided according to the types of transposition. Transposition types are subdivided according to their unilateral or bilateral status (Table 1).

Table 1. Gender distribution of transposition types.

\begin{tabular}{lcccccc}
\hline \multicolumn{1}{c}{ Types of Transposition } & \multicolumn{2}{c}{ Female } & \multicolumn{2}{c}{ Male } & \multicolumn{2}{c}{ Total } \\
\hline Mx.C.P1 (Type 1) & $\mathrm{N}$ & $\%$ & $\mathrm{~N}$ & $\%$ & $\mathrm{~N}$ & 31.9 \\
Mx.C.P1 Unilateral (Type 1 U) & 14 & 36.8 & 8 & 25.8 & 22 & 86.4 \\
MX. C.P1 Bilateral (Type 1 B) & 13 & 92.9 & 6 & 75.0 & 19 & 13.6 \\
Mx.C.I2 (Type 2) & 13 & 7.1 & 2 & 25.0 & 3 & 42.0 \\
Mx.C to M1(Type 3) & 0 & 34.2 & 16 & 51.6 & 29 & 1.5 \\
Mx.C to 1 (Type 5) & 1 & 0.0 & 1 & 3.2 & 1 & 1.5 \\
Mn.12.C (Type 6) & 10 & 26.3 & 0 & 0.0 & 1 & 23.2 \\
Mn.12.C Unilateral (Type 6 U) & 9 & 90.0 & 6 & 100.0 & 15 & 93.8 \\
Mn.12.C Bilateral (Type 6 B) & 1 & 10.0 & 0 & 0.0 & 1 & 6.2 \\
\multicolumn{1}{c}{ Total } & 38 & 100.0 & 31 & 100.0 & 69 & 100.0 \\
\hline
\end{tabular}

Mx.C.P1: Maxillary Canine-First Premolar; Mx.C.I2: Maxillary Canine-Lateral Incisor; Mx.C.I1: Maxillary Canine-Central Incisor; Mx.C.M1: Maxillary Canine-First Molar; Mn.12.C: Mandibular Canine-Lateral Incisor; Unilateral: U; Bilateral: B.

The upper jaw contained $76.7 \%$ of the transposed canine teeth. No statistically significant difference was found according to the sexes $(\mathrm{p}=0.496)$. Transposed canine teeth were more frequently observed 
unilaterally $(89 \%)$ or on the left side $(60 \%)$. Although transposition was observed more on the left side in both sexes, the relationship between them was not statistically significant $(p=0.464)$.

The most commonly observed transposition was maxillary canine-lateral incisor (42\%). Transposition type was examined according to gender and the side distribution, but the type 3 and 5 classifications were excluded from the statistical evaluation due to the presence of only one patient. The relationship between type 1, 2 and 6 transposition types and gender was not statistically significant ( $\mathrm{p}>0.05)$. Although transposition was more observed on the left side in unilateral cases (type $1 \mathrm{U}, 2,6 \mathrm{U}$ ), there was no significant difference in left- or right-sided distribution $(\mathrm{p}>0.05)$ (Table 2$)$.

Table 2. Side distributions of transposition types

\begin{tabular}{lcccccc}
\hline \multicolumn{1}{c}{ Types of Transposition } & \multicolumn{2}{c}{ Right } & \multicolumn{2}{c}{ Left } & \multicolumn{2}{c}{ Total } \\
& $\mathrm{N}$ & $\%$ & $\mathrm{~N}$ & $\%$ & $\mathrm{~N}$ & $\%$ \\
\hline Mx.C.P1 Unilateral (Type 1 U) & 7 & 26.9 & 12 & 30.8 & 19 & 29.2 \\
Mx.C.I2 Unilateral (Type 2) & 12 & 46.2 & 17 & 43.6 & 29 & 44.6 \\
Mx.C to M1 (Type 3) & 1 & 3.9 & 0 & 0.0 & 1 & 1.5 \\
Mx.C to 1 1 (Type 5) & 0 & 0.0 & 1 & 2.6 & 1 & 1.5 \\
Mn.12.C Unilateral (Type 6 U) & 6 & 23,1 & 9 & 23.1 & 15 & 23.1 \\
$\quad$ Total & 26 & 100.0 & 39 & 100.0 & 65 & 100.0 \\
\hline
\end{tabular}

Mx.C.P1: Maxillary Canine-First Premolar; Mx.C.I2: Maxillary Canine-Lateral Incisor; Mx.C.I 1: Maxillary CanineCentral Incisor; Mx.C.M1: Maxillary Canine-First Molar; Mn.12.C: Mandibular Canine-Lateral Incisor; Unilateral: U; Bilateral: B.

When transposition-related dental anomalies were examined, $49.3 \%$ of 69 patients had retained primary canine teeth, $20.3 \%$ had congenitally missing teeth excluding third molars, and $11.6 \%$ had peg-shaped or microdont lateral incisors. Impacted teeth excluding third molars were observed in $11.6 \%$ of cases and taurodontism was observed in $7.3 \%$. None of the patients had supernumerary teeth. Transposition types and related dental anomalies are shown in Tables 3 and 4. Retained primary canine teeth had the highest percentage in all transposition types. The upper right and left lateral teeth were most often missing congenitally. A significant correlation was detected between the types 1, 2, and 6 transposition classifications and dental anomalies only in the case of peg-shaped lateral teeth $(p=0.025)$. Two patients with canine transposition in the upper jaw had a cleft.

Table 3. Prevalence of agenesis, peg-shaped and microdont incisors, taurodontism, retained primary canine and impaction.

\begin{tabular}{|c|c|c|c|c|c|c|c|c|c|c|c|c|}
\hline \multirow[t]{2}{*}{ Types of Transposition } & \multicolumn{2}{|c|}{ Agenesis } & \multicolumn{2}{|c|}{ PS / MI } & \multicolumn{2}{|c|}{ Taurodontism } & \multicolumn{2}{|c|}{ RPC } & \multicolumn{2}{|c|}{ Impaction } & \multicolumn{2}{|c|}{ Total* } \\
\hline & $\mathrm{N}$ & $\%$ & $\mathrm{~N}$ & $\%$ & $\mathrm{~N}$ & $\%$ & $\mathrm{~N}$ & $\%$ & $\mathrm{~N}$ & $\%$ & $\mathrm{~N}$ & $\%$ \\
\hline Mx.C.P1 (Type 1) & $5 / 22$ & 22.7 & $1 / 22$ & 4.6 & $4 / 22$ & 18.2 & $9 / 22$ & 40.9 & $1 / 22$ & 4.6 & 22 & 31.9 \\
\hline Mx.C.P1 Unilateral (Type 1 U) & $4 / 19$ & 21.0 & $1 / 19$ & 5.3 & $4 / 19$ & 21.1 & $8 / 19$ & 42.1 & $1 / 19$ & 5.3 & 19 & 86.4 \\
\hline Mx.C.P1 Bilateral (Type 1 B) & $1 / 3$ & 33.3 & $0 / 3$ & 0.0 & $0 / 3$ & 0.0 & $1 / 3$ & 33.3 & $0 / 3$ & 0.0 & 3 & 13.6 \\
\hline Mx.C.I2 (Type 2 ) & $7 / 29$ & 24.1 & $7 / 29$ & 24.1 & $1 / 29$ & 3.5 & $13 / 29$ & 44.8 & $7 / 29$ & 20.7 & 29 & 42.0 \\
\hline Mx.C to M1(Type 3) & $0 / 1$ & 0.0 & $0 / 1$ & 0.0 & $0 / 1$ & 0.0 & $1 / 1$ & 100.0 & $0 / 1$ & 0.0 & 1 & 1.5 \\
\hline Mx.C to 11 (Type 5) & $0 / 1$ & 0.0 & $0 / 1$ & 0.0 & $0 / 1$ & 0.0 & $1 / 1$ & 100.0 & $0 / 1$ & 0.0 & 1 & 1.5 \\
\hline Mn.12.C (Type 6) & $2 / 16$ & 12.5 & $0 / 16$ & 0.0 & $0 / 16$ & 0.0 & $10 / 16$ & 62.5 & $1 / 16$ & 6.6 & 16 & 23.2 \\
\hline Mn.12.C Unilateral (Type $6 \mathrm{U}$ ) & $2 / 15$ & 13.3 & $0 / 15$ & 0.0 & $0 / 15$ & 0.0 & $9 / 15$ & 60.0 & $1 / 15$ & 6.7 & 15 & 93.8 \\
\hline Mn.12.C Bilateral (Type 6 B) & $0 / 1$ & 0.0 & $0 / 1$ & 0.0 & $0 / 1$ & 0.0 & $1 / 1$ & 100.0 & $0 / 1$ & 0.0 & 1 & 6.2 \\
\hline Total & $14 / 69$ & 20.3 & $8 / 69$ & 11.6 & $5 / 69$ & 7.3 & $34 / 69$ & 49.3 & $8 / 69$ & 11.6 & 69 & 100.0 \\
\hline
\end{tabular}

* Some patients have more than one dental anomaly; RPC: Retained Primary Canine; PS/MI: Peg-Shaped and Microdont Incisors; Mx.C.P1: Maxillary Canine-First Premolar; Mx.C.I2: Maxillary Canine-Lateral Incisor; Mx.C.I 1: Maxillary Canine-Central Incisor; Mx.C.M1: Maxillary Canine-First Molar; Mn.12.C: Mandibular Canine-Lateral Incisor; Unilateral: U; Bilateral: B. 
Table 4. All transposition cases and findings for tooth type.

\begin{tabular}{|c|c|c|c|c|c|c|c|c|}
\hline Gender & Age & Side & Tooth & Agenesis & PML & $\mathbf{R C}$ & Impaction & Taurodontism \\
\hline \multicolumn{9}{|l|}{ Type 1} \\
\hline Male & 13 & Left & 23 & & & & & \\
\hline Male & 13 & Right & 13 & $12,22,31,32,41,42$ & & 53 & & $16,26,36,46$ \\
\hline Female & 13 & Right & 13 & & & 53 & & \\
\hline Female & 12 & Right & 13 & 22 & & & 45 & \\
\hline Male & 13 & Right & 13 & & & 53 & & 16,26 \\
\hline Female & 15 & Left & 23 & $22,32,33$ & & 63 & & \\
\hline Female & 6 & Left & 23 & 22 & & & & \\
\hline Female & 14 & Left & 23 & & & & & \\
\hline Female & 14 & Right & 13 & & & 53 & & \\
\hline Female & 14 & Left & 23 & & & 63 & & $17,27,36,47$ \\
\hline Male & 12 & Left & 23 & & & 63 & & \\
\hline Female & 9 & Left & 23 & & & & & \\
\hline Female & 10 & Left & 23 & & & & & 16,26 \\
\hline Male & 15 & Right & 13 & & & & & \\
\hline Female & 13 & Left & 23 & & 12,22 & & & \\
\hline Male & 14 & Left & 23 & & & & & \\
\hline Female & 12 & $\mathrm{~L}$ & 23 & & & & & \\
\hline Female & 10 & Left & 23 & & & 63 & & \\
\hline Female & 8 & Right & 13 & & & & & \\
\hline Male & 10 & $\mathrm{R}+\mathrm{L}$ & 13,23 & & & & & \\
\hline Female & 9 & $\mathrm{R}+\mathrm{L}$ & 13,23 & & & & & \\
\hline Male & 13 & $\mathrm{R}+\mathrm{L}$ & 13,23 & 15,25 & & 53,63 & & \\
\hline \multicolumn{9}{|l|}{ Type 2} \\
\hline Male & 14 & Right & 13 & & & 53 & & \\
\hline Male & 12 & Left & 23 & & & 63 & & \\
\hline Male & 13 & Left & 23 & & & 63 & & \\
\hline Male & 14 & Left & 23 & & & 53,63 & 13 & \\
\hline Male & 15 & Left & 23 & & & 63 & & \\
\hline Female & 10 & Left & 23 & & & & & \\
\hline Male & 15 & Right & 13 & 12 & & & & \\
\hline Female & 15 & Left & 23 & & 22 & & & \\
\hline Female & 13 & Right & 13 & 22 & 12 & 53 & & \\
\hline Female & 12 & Left & 23 & & 22 & & & \\
\hline Female & 13 & Right & 13 & 42 & & 53 & & \\
\hline Female & 10 & Left & 23 & $12,15,22,25,31,35,45$ & & & & \\
\hline Female & 12 & Left & 23 & & 12,22 & & & \\
\hline Male & 10 & Right & 13 & & & & 22 & \\
\hline Male & 10 & Right & 13 & & & & & \\
\hline Female & 15 & Left & 23 & & & & & \\
\hline Male & 13 & Left & 23 & 12 & & 53,63 & & \\
\hline Male & 11 & Right & 13 & & & & & \\
\hline Male & 11 & Left & 23 & & & & 13 & \\
\hline Male & 10 & Right & 13 & & & & 11,12 & \\
\hline Male & 12 & Right & 13 & & 12 & 53 & & \\
\hline Male & 17 & Left & 23 & 31,41 & & 63 & & \\
\hline Female & 16 & Right & 13 & & & 53 & & \\
\hline Female & 10 & Left & 23 & & & & 13,35 & 16,26 \\
\hline Female & 11 & Right & 13 & & & 53 & & \\
\hline Female & 10 & Right & 13 & & & & & \\
\hline Female & 14 & Left & 23 & 12 & 22 & 63 & 25 & \\
\hline Male & 13 & Left & 23 & & & & & \\
\hline Male & 11 & Left & 23 & & 22 & & & \\
\hline
\end{tabular}

Type 3 


\begin{tabular}{|c|c|c|c|c|c|c|}
\hline Male & 13 & Right & 13 & & 53 & \\
\hline \multicolumn{7}{|l|}{ Туре 5} \\
\hline Female & 14 & Left & 23 & & 63 & \\
\hline \multicolumn{7}{|l|}{ Type 6} \\
\hline Female & 12 & Left & 33 & & 73 & \\
\hline Female & 11 & Right & 43 & & 83 & \\
\hline Female & 11 & Left & 33 & & & \\
\hline Male & 9 & Right & 43 & & & \\
\hline Female & 12 & Right & 43 & & 83 & \\
\hline Female & 11 & Left & 33 & 45 & 83 & \\
\hline Male & 7 & Right & 43 & & & \\
\hline Female & 12 & Left & 33 & & 73 & \\
\hline Male & 14 & Left & 33 & & 73 & \\
\hline Male & 15 & Left & 33 & 45 & 73 & 13 \\
\hline Male & 10 & Left & 33 & & & \\
\hline Female & 8 & Left & 33 & & & \\
\hline Female & 13 & Right & 43 & & 83 & \\
\hline Female & 11 & Left & 33 & & 73 & \\
\hline Female & 11 & Right & 43 & & & \\
\hline Female & 11 & $\mathrm{R}+\mathrm{L}$ & 33,43 & & 73,83 & \\
\hline
\end{tabular}

PML: Peg-Microdont Lateral; RC: Retained Canine; R+L: Right and Left.

\section{Discussion}

Canine transposition is a rather uncommon dental anomaly among young individuals, but detection it during early childhood is important. In our study, the prevalence of canine transposition was $0.6 \%$. When the studies on canine transposition in Turkish population are examined, it is seen that the prevalence varies between $0.27-0.41 \%[3,9,14]$. Although the present study group consisted of patients between the ages of 6-17 years, it is thought that the presence of quite a wide age range (6-40 years) and different sample sizes in other studies constituted the differences in prevalence. Furthermore, considering the possibility of subsequent transposition of canine teeth in patients who have no canine eruption activity, there is a possibility that this ratio would change slightly.

Canine transposition was more common in girls than boys (55.1\%), supporting the findings of studies conducted in different populations $[5,13,15,21]$. This is because girls are more likely to present to clinics to search for orthodontic treatment for aesthetic purposes. Transposition was higher in males in a study that included orthodontic patients (4:3) [22]. It has been reported that these differences in gender are related to genes [11]; however, other studies indicate that gender does not make a significant difference $[8,14,20]$.

It has been stated that the higher bone density of the lower jaw prevents the transposition of teeth and that transposition is seen in the lateral-canine region where the bone is more porous than that in the molar region. Due to the lower bone density in the upper jaw, the localization of transposition types in the upper jaw is not limited, as seen in the lower jaw [20]. In our study, transposition was mostly seen in the upper jaw $(76.7 \%)$ and was unilateral $(89 \%)$. These rates were reported to be $45.5-95 \%$ in the upper jaw and $5-54.5 \%$ in the lower jaw in the studies [14-16,23]. The unilateral incidence rate was reported to be $85-94.4 \%$ $[14,16,21,23]$, which was similar to the result of our study. The researchers reported that bilateral cases account for $5.3-14.9 \%$ of transposition patients [3,19]. It was previously described that the human face is not symmetrical; therefore, the arch length is affected and may result in unilateral transposition in some severe cases [11]. In our study, bilateral transposition cases were observed more often in the upper jaw (lower in one and upper in three patients), as supported by previous studies [24,25]. 
When transpositions were evaluated according to localization, canine transpositions were more frequent on the left side $(60 \%)$. Some studies support this result [3,13,23], while other researchers have reported no difference between the sides [14].

According to the Peck's classification [5], the most common transposition type was reported as type 1 transposition $(58-70 \%)[5,10,13,16]$. In our study, as in another studies conducted in Turkey [3,14], type 2 transposition was the most common. In a study of patients aged 6-15 years, type I transpositions were reported more on the left side [4], which is similar to our study, but we found no significant difference (p>0.05).

Although type 3 transposition is very rare, the early loss of permanent first molar teeth may cause transposition, but there are a few cases in the literature that report otherwise [5,14]. Type 5 transposition, defined as the transposition of the upper canine to the central incisor region, was observed in only one patient in our study. In the patient's records, it was determined that this patient's tooth was transposed to this area after trauma. Similar cases have been reported in the literature [5,8,26].

Transposition, which is very rare in the lower jaw (0.003\%), has been reported to be common unilaterally and between canine-lateral teeth region [16,23]. As a result of this study, the incidence of transposition in the lower jaw was $23.2 \%$, and bilateral transposition was detected in only one patient. Although transposition of the lower jaw was higher on the left side in this study, it was not statistically significant $(\mathrm{p}>0.05)$. Other studies have reported contradictory findings [3,14].

It is well-known that when a patient has a dental anomaly, other anomalies may accompany. A significant relationship has been reported between transposition and other dental anomalies [10]. According to the researchers, it was found that $38.1-63.6 \%$ of the patients also have retained primary canine teeth, 21.1$40 \%$ have congenitally missing teeth, 9.1-27\% have peg-shaped lateral teeth, $5.6-27.3 \%$ have impacted teeth, $5.3 \%$ have transmigrated teeth, 4.8-5.3\% have supernumerary teeth [3,10,14-16,23]. A meta-analysis study revealed the dental anomalies that are seen with transposition; however, no evidence was found that transposition is a syndrome with peg-shaped laterals, congenitally missing teeth, or impacted teeth [20].

In our research, retained primary canine teeth were the most common with transposition types, which was also expected. Similar results were reported in previous studies [3,10,21]. Prolonged retention of primary teeth is caused by inaccurate positioning of permanent teeth crypts because of delayed root resorption of primary teeth and delayed root resorption of primary teeth due to the permanent position of the transposed teeth [5,23]. Retained primary canine teeth were reported in $60 \%$ of type 1 cases and $22.2 \%$ of type 2 cases [14]. We detected retained canine teeth in $40.9 \%$ of type 1 cases and $44.8 \%$ of type 2 cases in our study.

The most common congenitally missing teeth in transposition cases are lateral incisors [1]. In the present study, 29 permanent teeth were found to be missing congenitally among the 69 cases, and 11 of them were maxillary lateral incisors (37.9\%); mandibular incisors accounted for only $31 \%$ of the missing teeth. Unilateral or bilateral missing lateral teeth were reported in $25 \%$ of type 1 cases [10], and similar results were observed in our study (22.7\%).

In patients with canine transposition in the upper jaw, it is thought that a genetic effect may play a role in the peg-shaped and microdont susceptibility of the upper lateral incisors [23]. In our study, peg-shaped lateral teeth were seen in $11.6 \%$, type 1 was seen in $4.6 \%$, and type 2 was seen in $24.1 \%$ of patients. In contrast, one study reported $67 \%$ of type 1 transposition patients and $7.1 \%$ of type 2 patients [23].

About $11.6 \%$ of patients with transposed canine teeth had impacted teeth and $37.5 \%$ of this ratio was composed of posterior teeth. Transposition of the teeth may be dependent on the presence of impacted teeth or may be independent. 
Researchers investigating the presence of taurodontism in other teeth of patients with transposed teeth have observed a significant relationship between taurodontic teeth and the type $1 \mathrm{U}$ group [4]. In our study, the presence of taurodontism was seen in $7.3 \%$ of patients and $80 \%$ of these patients had type $1 \mathrm{U}$ transposition.

A previous study reported canine transposition in $4.1 \%$ of cleft lip and palate patients [27]. In our study, transposition was observed in two non-sibling girls who were 6 and 12 years with a cleft upper jaw. In addition, it is known that transposition of the teeth occurs after trauma. In our study, $5.8 \%$ of the transposition cases consisted of patients with a history of trauma in the transposed area, which is similar to a previous study [3].

Generally, the age at which children are traumatized is a mixed dentition period in which growth and development are active. Many dental problems can be treated if diagnosed during this period. However, as the time for patients to refer to dentists is usually the age of 11-12 years, which is eruption time of the upper canines, children between the ages of 6-9 years with transposition accounted for only $8.7 \%$ of our study group. In a study, transposition cases between the ages of 8-9 were found in $69 \%$ of cases [19]. The reason for the low rate in our study is that the majority of our patient group consisted of patients 12-13 years. Therefore, the importance of following children during the mixed dentition period is emphasized. A multidisciplinary treatment approach may be necessary to obtain long-term aesthetic and functional results for transpositions detected during the late period.

\section{Conclusion}

The prevalence of canine transposition was found to be $0.6 \%$. Transposed canine teeth were mostly associated with retained primary canine teeth. In these cases, it should be kept in mind that canine teeth can be transposed. Although the transpositions are generally asymptomatic in children in the period of growth and development, the importance of early diagnosis is emphasized once again to prevent the development of transposition, which may cause various clinical problems and to prevent future dental problems.

\section{Authors' Contributions}

EO (D) 0000-0002-5160-7211 Conceptualization, Methodology, Investigation, Formal Analysis, Data curation, Writing - Original Draft Preparation and Visualization.

ZK (D) 0000-0002-3726-2392 Conceptualization, Methodology, Writing - Original Draft Preparation and Visualization.

All authors declare that they contributed to critical review of intellectual content and approval of the final version to be published.

\section{Financial Support}

None.

\section{Conflict of Interest}

The authors declare no conflicts of interest.

\section{References}

[1] Peck L, Peck S, Attia Y. Maxillary canine-first premolar transposition, associated dental anomalies and genetic basis. Angle Orthod 1993; 63(2):99-109.

[Q] Memon S, Fida M. Bilateral maxillary canine-first premolar transposition in permanent dentition. J Coll Physicians Surg Pak 2014; 24(8):597-9. https://doi.org/08.2014/JCPSP.597599 
[3] Celikoglu M, Miloglu O, Oztek O. Investigation of tooth transposition in a non-syndromic Turkish anatolian population: characteristic features and associated dental anomalies. Med Oral Patol Oral Cir Bucal 2010; 15(5):71620. https://doi.org/10.4317/medoral.15.e716

[4] Danielsen JC, Karimian K, Ciarlantini R, Melsen B, Kjaer I. Unilateral and bilateral dental transpositions in the maxilla-dental and skeletal findings in 63 individuals. Eur Arch Paediatr Dent 2015; 16(6):467-76. https://doi.org/10.1007/s40368-015-0196-6

[5] Peck S, Peck L. Classification of maxillary tooth transpositions. Am J Orthod Dentofacial Orthop 1995; 107(5):50517. https://doi.org/10.1016/s0889-5406(95)70118-4

[6] Serra-Serra G, Berini-Aytés L, Gay-Escoda C. Erupted odontomas: a report of three cases and review of the literature. Med Oral Patol Oral Cir Bucal 2009; 14(6):E299-303.

[7] Shapira Y, Kuftinec MM. Tooth transpositions - a review of the literature and treatment considerations. Angle Orthod 1989; 59(4):271-6.

[8] Weeks EC, Power SM. The presentations and management of transposed teeth. Br Dent J 1996; 181(11-12):421-4. https://doi.org/10.1038/sj.bdj.4809280

[9] Bilge NH, Yeşiltepe S, Törenek Ağırman K, Çağlayan F, Bilge OM. Investigation of prevalence of dental anomalies by using digital panoramic radiographs. Folia Morphol 2018; 77(2):323-8. https://doi.org/10.5603/FM.a2017.0087

[10] Budai M, Ficzere I, Gábris K, Tarjan I. Frequency of transposition and its treatment at the Department of Orthodontics of Semmelweis University in the last five years. Fogorv Sz 2003; 96(1):2 1-4.

[11] Papadopoulos MA, Chatzoudi M, Kaklamanos EG. Prevalence of tooth transposition. A meta-analysis. Angle Orthod 2010; 80(2):275-85. https://doi.org/10.2319/052109-284.1

[12] Ruprecht A, Batniji S, El-Neweihi E. The incidence of transposition of teeth in dental patients. J Pedod 1985; 9(3):244-9.

[13] Shapira Y, Kuftinec MM. Maxillary tooth transpositions: characteristic features and accompanying dental anomalies. Am J Orthod Dentofacial Orthop 2001; 119(2):127-34. https://doi.org/10.1067/mod.2001.111223

[14] Yilmaz HH, Tukkahraman H, Sayin MO. Prevalence of tooth transpositions and associated dental anomalies in Turkish population. Dentomaxillofac Radiol 2005; 34(1):32-5. https://doi.org/10.1259/dmfr/57695636

[15] Umweni AA, Ojo MA. The frequency of tooth transposition in Nigerians, its possible aetiologic factors and clinical implications. J Dent Assoc S Afr 1997; 52(9):551-4.

[16] Ely NJ, Sherriff M, Cobourne MT. Dental transposition as a disorder of genetic origin. Eur J Orthod 2006; 28(2):14551. https://doi.org/10.1093/ejo/cjio92

[17] Plunkett DJ, Dysart PS, Kardos TB, Herbison GP. A study of transposed canines in a sample of orthodontic patients. Br J Orthod 1998; 25(3):203-8. https://doi.org/10.1093/ortho/25.3.203

[18] Ciarlantini R, Melsen B. Maxillary tooth transposition: correct or accept?. Am J Orthod Dentofacial Orthop 2007; 132(3):385-94. https://doi.org/10.1016/j.ajodo.2007.04.011

[19] Laganà G, Venza N, Borzabadi-Farahani A, Fabi F, Danesi C, Cozza P. Dental anomalies: prevalence and associations between them in a large sample of non-orthodontic subjects: a cross-sectional study. BMC Oral Health 2017; 17(1):62. https://doi.org/10.1186/s12903-017-0352-y

[20] Papadopoulos MA, Chatzoudi M, Karagiannis V. Assessment of characteristic features and dental anomalies accompanying tooth transposition: a meta-analysis. Am J Orthod Dentofacial Orthop 2009; 136(3):308.e1-10. https://doi.org/10.1016/j.ajodo.2008.12.017

[21] Cho SY, Chu V, Ki Y. A retrospective study on 69 cases of maxillary tooth transposition. J Oral Sci 2012; 54(2):197203. https://doi.org/10.2334/josnusd.54.197

[22] Kavadia-Tsatala S, Sidiropoulou S, Kaklamanos EG, Chatziyanni A. Tooth transpositions associated with dental anomalies and treatment management in a sample of orthodontic patients. J Clin Pediatr Dent 2003; 28(1):19-25. https://doi.org/10.17796/jcpd.28.1.c320v565x8413n7g

[23] Chattopadhyay A, Srinivas K. Transposition of teeth and genetic etiology. Angle Orthod 1996; 66(2):147-52.

[24] Shapira Y, Kuftinec MM. Orthodontic management of mandibular canine-incisor transposition. Am J Orthod 1983; 83(4):271-6. https://doi.org/10.1016/0002-9416(83)90221-x

[25] Shapira Y, Finkelstein T, Kadry R, Schonberger S, Shpack N. Mandibular symmetrical bilateral canine-lateral incisors transposition: its early diagnosis and treatment considerations. Case Rep Dent 2016; 2016:5043801. https://doi.org/10.1155/2016/5043801

[26] Gholston LR, Williams PR. Bilateral transposition of maxillary canines and lateral incisors: a rare condition. ASDC J Dent Child 1984; 51(1):58-63.

[27] Helióvaara A, Ranta R, Rautio J. Dental abnormalities in permanent dentition in children with submucous cleft palate. Acta Odontol Scand 2004; 62(3):129-31. https://doi.org/10.1080/00016350410006572 